\title{
Coexistence of Multiple Trauma Diagnoses in One Scene
}

\author{
Muhammet Sayan', Mahmut Tokur', Şevki Mustafa Demiröz ${ }^{2}$ \\ 'Department of Thoracic Surgery, Kahramanmaraş Sütçü İmam University School of Medicine, Kahramanmaraş, Turkey \\ 2Department of Thoracic Surgery, Atatürk Chest Diseases and Thoracic Surgery Training and Research Hospital, Ankara, Turkey
}

A 21-year-old male patient was transferred to the emergency department due to a traffic accident. Flail chest, minor subcutaneus emphysema, tachycardia, and tachypnea were revealed on thoracic physical examination. Pneumothorax, minor hemothorax, multiple rib fractures, traumatic pulmonary lacerations, subcutaneous emphysema, pulmonary contusion, and intrapulmonary hematoma were detected on a thoracic computed tomography (Figure 1). In addition, brain edema and pelvic fractures were seen on another radiologic imaging technique. The patient was intubated due to a low Glasgow Coma Scale score of 8, and tube thoracostomy operation was performed on the left hemithorax.He was then admitted to the intensive care unit where he was connected to a mechanical ventilator. The patient died on the tenth day after hospitalization due to ventilator-associated pneumonia and sepsis.

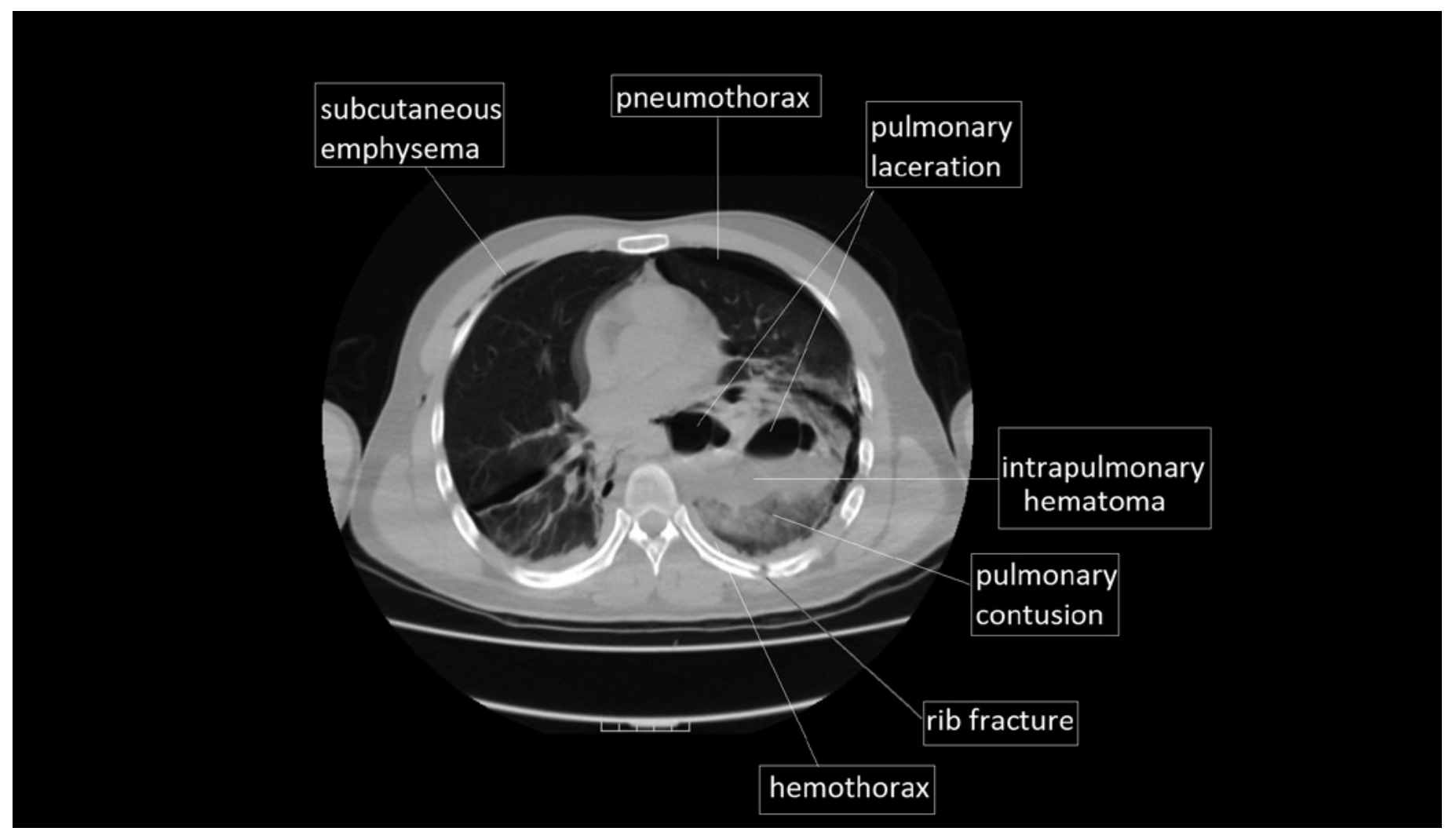

Figure 1. Various types of thoracic trauma seen on thoracic computed tomography

Correspondence to: Muhammet Sayan e-mail: drsayann@gmail.com 